Gut and Liver, Vol. 10, No. 4, July 2016, pp. 487-488

\title{
The Efficiency of Intravenous Iron Therapy in Korean Inflammatory Bowel Disease Patients
}

\author{
Kyeong Ok Kim \\ Department of Internal Medicine, Yeungnam University College of Medicine, Daegu, Korea
}

See "Comparison of the Efficacies of Parenteral Iron Sucrose and Oral Iron Sulfate for Anemia Patients with Inflammatory Bowel Disease in Korea" by Yoo Min Han, et al. on page 562, Vol. 10. No. 4, 2016

Inflammatory bowel disease (IBD) is associated with chronic intestinal inflammation, complications, and variable extraintestinal manifestations. ${ }^{1-3}$ Although anemia is one of the most common extraintestinal manifestations and can affect quality of life in patients with IBD, it's clinical importance has been underestimated. However, in a recently issued Western guideline, which placed focused on the morbidity associated with anemia, regular assessment and appropriate management, such as, intravenous iron supplementation, were recommended. ${ }^{4}$

Iron deficiency anemia (IDA) is the most common cause of anemia with reported prevalence of $30 \%$ to $90 \%$ in IBD patients and iron supplementation should be initiated in addition to control disease, as soon as iron deficiency is detected. ${ }^{5-7}$

To correct IDA, iron supplementation, erythropoietin administration, and red blood cell transfusions could be considered. ${ }^{6}$ Iron may be administered via two routes, that is, orally or by intravenous supplementation, although some disagreement exists regarding the efficacy and safety of these routes. Oral iron is equivalent to and cheaper than intravenous iron, but oral iron has a limitation of gut absorption and nonabsorbed iron can be toxic in the presence of mucosal inflammation and aggravate disease. ${ }^{8}$ Furthermore, oral iron is associated with slow response and intolerance. ${ }^{9}$ Intravenous iron, on the other hand, is better tolerated and more effective at normalizing hemoglobin and ferritin levels in the short term, though this is dependent on hemoglobin level and body weight. ${ }^{9}$ Based on published information, international guidelines have been issued to the effect that intravenous administration is preferred. ${ }^{4,9}$ However, physicians are reluctant to use intravenous iron because of its rare and fatal side effect. ${ }^{9}$ However, nowadays, new effective, safe prepara- tions are available. ${ }^{6}$

Much of the data concerning these issues has resulted from Western studies. In that point, the study performed by Han et al. ${ }^{10}$ has clinical significance for the management of Asian IBD patients with IDA. This comparative observational study was undertaken to assess and compare the efficacies of parenteral and oral iron therapy in Korean IBD patients. The most common indication for parenteral iron therapy was intolerance to oral iron therapy, which had a prevalence of $24 \%$, followed by severe anemia and disease or nonresponsiveness to oral iron in $22 \%$. Furthermore, these findings were consistent with those of a previous study except the starting level of hemoglobin, in which it was suggested that intravenous iron should be considered in cases with active disease, intolerance or failure of oral iron, and in those needing rapid response. ${ }^{11}$ In this study, the mean hemoglobin level was $8.4 \mathrm{~g} / \mathrm{dL}$ in intravenous iron group and it is lower than the recommended indication of guidelines $(\leq 10.5 \mathrm{~g} / \mathrm{dL}){ }^{11}$ It could be associated with the national health insurance system about parenteral iron usage in Korea.

Response rate to iron treatment was $61.0 \%$ for intravenous and $82.9 \%$ oral iron, and this response rate to intravenous iron was similar to those reported in the West, although response to oral iron was higher than in a previous study. ${ }^{12,13}$ However, because baseline hemoglobin levels and treatment duration differed in study groups, Han et al. ${ }^{10}$ thought that it could not be an exact comparison of efficacy using simply response rates, so instead of direct comparison of response rate, they used the life table method in terms of total dose of iron and time spent to achieve the end point. In addition, they also assess with two clinical outcomes for the exact comparison of efficacy: that

\footnotetext{
Correspondence to: Kyeong Ok Kim

Department of Internal Medicine, Yeungnam University College of Medicine, 170 Hyeonchung-ro, Nam-gu, Daegu 42415, Korea

Tel: +82-53-620-3830, Fax: +82-53-654-8386, E-mail: kokim@yu.ac.kr

pISSN 1976-2283 eISSN 2005-1212 http://dx.doi.org/10.5009/gnl16205

@ This is an Open Access article distributed under the terms of the Creative Commons Attribution Non-Commercial License (http://creativecommons.org/licenses/by-nc/4.0) which permits unrestricted non-commercial use, distribution, and reproduction in any medium, provided the original work is properly cited.
} 
firstly, generally used outcomes with increase in hemoglobin $\geq 2 \mathrm{~g} / \mathrm{dL}$ and secondly, the rise in hemoglobin $\geq 20 \%$ from base line. Although statistical significance was not achieved, it was concluded parenteral iron therapy appeared to be more efficient (hazard ratio, 1.552; 95\% confidence interval, 0.884 to 2.851), furthermore, to achieve the secondary outcomes, parenteral iron increased needs lower doses and in shorter times than oral iron ( $p=0.034$ and $p=0.046$, respectively). In other words, when equivalent doses of iron were supplied, intravenous iron appeared to be more effective.

Han et al. ${ }^{10}$ also suggested ulcerative colitis (UC) and a low initial hemoglobin level $(<10 \mathrm{~g} / \mathrm{dL})$ predict good response to iron therapy and that the route of administration was not a significant predictor of response. However, no explanation was offered as to why UC predicted better response, although it was suggested that lower hemoglobin indicated better response because of its association with a higher erythropoietin level. Nevertheless, firm predictors of response to intravenous iron were not identified, and it should be noted that is important for identifying appropriate indications for intravenous iron treatment.

Quality of life of IBD patients is being increasingly realized, and treatment of anemia accompanying IBD has become an important issue. Because few studies have been conducted on anemia associated with IBD in Asians, the study performed by Han et al. ${ }^{10}$ could provide valuable information on the treatment of IDA in Asian IBD patients. However, their study has several limitations in the study. First, the response rate did not accurately reflect efficacy in IDA, because iron status and other markers of inflammation were not measured, it is possible non-IDA patients were included. Second, the regimens used may have been variable in terms of including dosage and dosage intervals. Third, their study was limited by its retrospective, observational nature, and as a result other possible predictors of response, such as, disease activity, could not be fully assessed. Fourth, treatment associated adverse effects could not be evaluated. Nonetheless, the study aroused interest about the management of anemia in Korean IBD patients. Based on results at hand, it is evident that studies are needed to determine indications for the parenteral route, agent types, and dosing, and to elaborate safety issues associated with iron therapy in Asian IBD patients.

\section{CONFLICTS OF INTEREST}

No potential conflict of interest relevant to this article was reported.

\section{REFERENCES}

1. Kim NH, Jung YS, Moon CM, et al. Long-term clinical outcomes of Korean patient with Crohn's disease following early use of infliximab. Intest Res 2014;12:281-286.

2. Su CG, Judge TA, Lichtenstein GR. Extraintestinal manifestations of inflammatory bowel disease. Gastroenterol Clin North Am 2002;31:307-327.

3. Jung YS, Park JH, Kim HJ, et al. Insufficient knowledge of Korean gastroenterologists regarding the vaccination of patients with inflammatory bowel disease. Gut Liver 2014;8:242-247.

4. Gasche C, Berstad A, Befrits R, et al. Guidelines on the diagnosis and management of iron deficiency and anemia in inflammatory bowel diseases. Inflamm Bowel Dis 2007;13:1545-1553.

5. Kulnigg S, Gasche C. Systematic review: managing anaemia in Crohn's disease. Aliment Pharmacol Ther 2006;24:1507-1523.

6. Gomollón F, Gisbert JP. Current management of iron deficiency anemia in inflammatory bowel diseases: a practical guide. Drugs 2013;73:1761-1770.

7. Kim B, Park SJ, Hong SP, Cheon JH, Kim TI, Kim WH. Overlooked management and risk factors for anemia in patients with intestinal Behçet's disease in actual clinical practice. Gut Liver 2015;9:750755.

8. Carrier J, Aghdassi E, Cullen J, Allard JP. Iron supplementation increases disease activity and vitamin $\mathrm{E}$ ameliorates the effect in rats with dextran sulfate sodium-induced colitis. J Nutr 2002;132:3146-3150.

9. Lee TW, Kolber MR, Fedorak RN, van Zanten SV. Iron replacement therapy in inflammatory bowel disease patients with iron deficiency anemia: a systematic review and meta-analysis. J Crohns Colitis 2012;6:267-275.

10. Han YM, Yoon H, Shin CM, et al. Comparison of the efficacies of parenteral iron sucrose and oral iron sulfate for anemic patients with inflammatory bowel disease in Korea. Gut Liver 2016;10:562568

11. Gomollón F, Gisbert JP. Intravenous iron in inflammatory bowel diseases. Curr Opin Gastroenterol 2013;29:201-207.

12. Kulnigg S, Stoinov S, Simanenkov V, et al. A novel intravenous iron formulation for treatment of anemia in inflammatory bowel disease: the ferric carboxymaltose (FERINJECT) randomized controlled trial. Am J Gastroenterol 2008;103:1182-1192.

13. Schröder 0, Mickisch 0, Seidler U, et al. Intravenous iron sucrose versus oral iron supplementation for the treatment of iron deficiency anemia in patients with inflammatory bowel disease: a randomized, controlled, open-label, multicenter study. Am J Gastroenterol 2005;100:2503-2509. 